\title{
СЛОВО О СУЩЕМ В ФИЛОСОФИИ АРИСТоТЕЛЯ
}

\section{В.В. Прокопенко}

Вопросы о том, что такое сущее, что значит «быть», что именно есть и каким способом существующее существует, занимают центральное положение в теоретической философии Аристотеля. Представление категории сущего в философии Аристотеля можно назвать фундаментальным для всей западной метафизической традиции. Обсуждение, комментирование и критика аристотелевских высказываний о сущем еще в Перипатосе сложились в богатейшую традицию, которая пополняется и сегодня, не менее активно, чем в древности или средневековье. Современная литература по этим вопросам практически необозрима: к примеру, «вашингтонская библиография» Аристотеля (University of Washington), включающая литературу на основных европейских языках за период с 1954 по 2004 г., насчитывает около сотни (99) названий по проблеме сущего у Аристотеля (выделим наиболее фундаментальные и получившие широкий отклик работы Р. Дэнси [18] и Дж. Оуэнса [20], к которым добавим обобщающий труд Ч. Кана об использовании глагола «быть» в греческом языке [19]).

В отечественной историко-философской литературе интерес к данной проблеме заметно оживился в последние годы, что, не в последнюю очередь, связано с работой по совершенствованию украинской философской терминологии, предпринятой группой философов и филологов, объединившихся вокруг журналов «Sententiae», «Філософська думка» и издательства «Дух і Літера». Знаковым событием в их деятельности стал выход в свет первого тома украиноязычной версии «Европейского словаря непереводимостей», в котором вопросу о сущем у Аристотеля посвящена фундаментальная статья Барбары 
Кассен [7, с. 127-139]. В свете планов по дальнейшему переводу сочинений Аристотеля на украинский язык большой интерес представляют варианты перевода аристотелевских терминов, предложенные в статье Ирины Листопад [10].

С нашей стороны было бы самонадеянным претендовать на полное и окончательное раскрытие темы сущего у Аристотеля, потому мы ограничимся одной только терминологической стороной вопроса. Это не означает, что мы разделяем принципы радикальной «логологической» идеологии Б. Кассен и ее сторонников ${ }^{1}$. Для нас внимание к терминологической стороне вопроса - необходимое условие исторической корректности исследования, а ее игнорирование приводит к тому, что в некоторых современных исследованиях место собственно аристотелевской мысли занимают ее более поздние, чаще всего - схоластические, интерпретации. Из множества текстов Аристотеля мы обращаемся к тем, в которых проблематика сущего является доминирующей: очевидно, что это «Метафизика», в особенности книги $\Gamma$ и $\Delta$, а также «Категории» (главы 4 и 5).

Суждения Аристотеля о сущем с терминологической стороны во многом объективно определяются возможностями греческого языка. Прежде всего, это касается глаголов, которые мы знаем, как «быть» и «существовать»: в греческом языке нет двух различных глаголов для выражения понятий бытия и существования, как в русском или других новых языках, поэтому при чтении аристотелевских текстов нам придется руководствоваться «правилом Германна» (Карл Фридрих Германн, немецкий филолог, ввел это правило в 1801 году), согласно которому глагол віні прочитывается и как «быть», и как «существовать», в зависимости от контекста. Эта особенность греческого языка, выражающая нераздельность бытия в мышлении ранних греческих философов и уходящего в архаику греческого видения ко-

\footnotetext{
${ }^{1}$ Логология у Б. Кассен используется не в традиционном значении учения о Логосе в христологии Нового Завета. Под влиянием позднего Хайдеггера, семинары которого она посещала, Кассен пришла к убеждению, что дискурс не является репрезентацией реальности, наоборот, сам дискурс создает бытие, и потому его значение понимается только задним числом, из мира, который этим дискурсом создается. «Я предлагаю назвать логологией, термином, заимствованным у Новалиса, это восприятие онтологии как дискурса, это настоятельное указание на перформативную автономность языка и на порождаемый им эффект мира» [8, с. 10]. В академических кругах эти взгляды встретили настолько сильное неприятие, что А.А.Россиус, известный филолог-классик, который и перевел процитированную книгу на русский язык, даже назвал ее «настоящей гадостью» и «мошенничеством» $[12]$.
} 
смоса как единого и целостного, не мешала ни Анаксагору, ни даже еще Платону. Однако когда Аристотель принимается за решение вопроса о бытии посредством разработанного им метода различений и классификаций (А.Ф.Лосев говорит о нем как о «дизъюнктивно-дескриптивном» методе), то перед ним возникают серьезные трудности, связанные с невозможностью говорить о бытии в различных смыслах относительно различных его форм. Особенно явными становятся эти трудности в контексте специфического подхода Аристотеля к синтезу определений, исходящему из наличного словоупотребления («о сущем

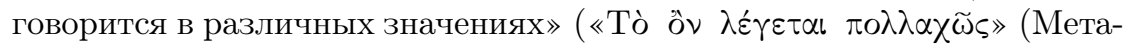
физика 1028a 10) $)^{2}$, заставляя вспомнить будущее витгенштейновское: «значение есть употребление». Практики терминологического различения понятий бытия и существования, нетождественность которых уже начинает осознаваться Аристотелем, в его время еще не было. Аристотелю еще только предстояло найти слова для выражения этого различия.

Там, где в переводах на русский язык (перевод А.В. Кубицкого, отредактированный М.М. Иткиным) используются термины «бытие» или «сущее», на английский - «being» (W. Ross), сам Аристотель чаще всего употребляет слово हॉ̃ $а$, «есть» (Метафизика 994a 27, 994b 26, 1007a 21), иногда - òv, (gen. òvтos) (Метафизика 1008a 16), которое представляет собой причастие настоящего времени к віні́, «быть», так что «сущее» здесь никак не отличить от «бытия». Те случаи, в которых перевод на новые языки позволяет предположить существование этого различения у Аристотеля, при ближайшем рассмотрении оказываются модернизацией. Наиболее очевидный из таких случаев фрагмент (Метафизика 1017в), который в русском переводе звучит, как «бытие и сущее означают», в английском-«Again, „being“" and ,that which is", in these cases we have mentioned», у самого же Ари-

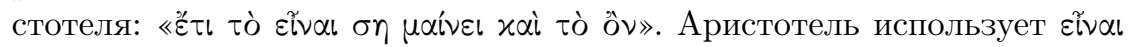
и то̀ ồ, различные по грамматике, но практически неразличимые по значению, формы одного и того же слова. Ясно, что само бытие для Аристотеля еще не субстантивировалось настолько, чтобы приобрести

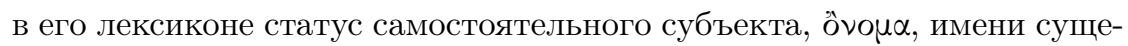
ствительного, и Аристотель чаще всего, говоря о бытии, пользуется инфинитивной формой глагола «есть»- «вंці» (Метафизика 1015b 5,

\footnotetext{
2 Здесь и далее Аристотель цитируется указанием на пагинацию Беккера по 4-х томному изданию в переводе на русский язык под ред. В.Ф. Асмуса [2] и 3.Н. Микеладзе [1] и в переводе на английский язык под ред. Дж. Барнса [15]. Греческий текст цитируется по изданию Aristotelis Opera [14].
} 


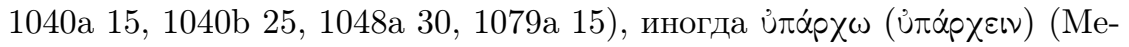
тафизика 1011b 21, 1012a 30, 1028a 35). Недостающую определенность глаголов Аристотель часто пытается восполнить введением согласованных слов, как, например, в случае использования словосочетания

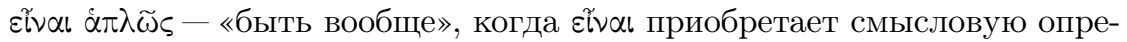
деленность «быть чем-то или как-то определенным».

Тò òv, сущее, Аристотель не включает в перечень своих десяти категорий именно потому, что оно не высказывается ни о чем в качестве признака. Сказать «Сократ существует» означает то же самое, что сказать просто «Сократ» - предикат существования не делает высказывание более содержательным. По замечанию Гилберта Райла,

В его [Аристотеля - В.П.] время слово «категория» означало то же, что наше слово «предикат» со всей неясностью и двусмысленностью этого существительного. Но перечень категорий у Аристотеля не являлся словарем всех существующих предикатов. Во всяком случае, было бы правдоподобным предположить, что сам Аристотель задумал его как перечень предельных типов предикатов [11, с. 328].

Сущее как таковое (сущее как сущее), тò ồ ñ̃ ồ (Метафизика 1003a 21) должно, как считает Аристотель, изучаться особой наукой, первой философией, поскольку она ищет высшие начала и первые причины, а отдельные науки, такие, как физика и математика, изучают только отдельные виды сущего, а не сущее как таковое. Это суждение, как и вся первая глава книги $\Gamma$, дают возможность понять Аристотеля так, как в будущем его поймет Фома: наряду с отдельными вещами существует некое высшее бытие, которое обладает более высоким уровнем существования, чем отдельные его виды и единичные вещи, по отношению к которым это высшее бытие выполняет роль порождающего начала.

Согласно этому бытие (esse) как «акт бытия» (actus essendi) есть принцип действительности бытия, т. е. не только существования (экзистенции), но также и всех актуально положенных в сущем содержаний бытия или совершенств бытия (perfectiones essendi), а поэтому и всей позитивности и актуальности, которая присуща сущему. Бытие есть «perfectissimum», «actualitas omnium perfectionum» (цит. по: [9, с. 75]).

Но ведь у самого Аристотеля вопрос о сущем разворачивается иначе:

Так вот, таким же точно образом и о сущем говорится в различных значениях, но всякий раз по отношению к одному началу; [...] Итак, сущее и единое - одно и то же, и природа у них одна, поскольку они сопутствуют друг другу так, как начало и причина, но не в том смысле, что они выражаемы через одно и то же определение [...] Действительно, одно и то же- «один человек» и «человек», «существующий 
человек» и «человек», и повторение в речи «он есть один человек» и «он есть человек» не выражает что-то разное (ясно же, что [«сущее»] не отделяется [от «единого»] ни в возникновении, ни в уничтожении), и точно так же «единое» [от «сущего» не отделяется]; так что очевидно, что присоединение их не меняет здесь смысла и что «единое»не есть здесь что-то другое по сравнению с сущим. Кроме того, сущность каждой вещи есть «единое» не привходящим образом, и точно так же она по существу своему есть сущее (Метафизика 1003b 5-33).

Для ответа на вопрос о существовании Аристотель привлекает еще одно слово - óvoí $\alpha$, которое выступает синонимом указанного единого. То единое, к которому сводятся значения сущего, - это сущность, как обычно и переводят óvбí $\alpha$ и Розанов, и Кубицкий в «Метафизике». А единое составляет либо род, $\dot{\eta} \nu$, сущность простая, либо отдельная вещь, составная чувственная сущность, причем об отдельном существовании родов Аристотель высказался достаточно определенно в своей критике платонического учения об идеях: они не обладают отдельным существованием. Для решения же вопроса о существовании сущности Аристотель обращается к тому же методу разделения. Основные зна-

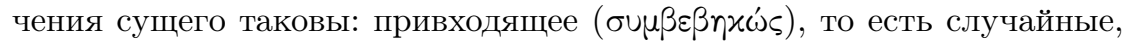
несобственные качества вещи; сущее в смысле истины и не-сущее в смысле лжи; разные виды категорий: сколько категорий, столько и типов высказывания о сущем; сущее в возможности и сущее в действительности.

А.Л. Доброхотов утверждает, что понятие óvбí $\alpha$ является ключом к проблеме сущего не только для Аристотеля, но и для всей традиции античной платонической мысли:

Сейчас важно отметить, что вопрос о том, что есть «сущее как су-
щее», Аристотель сводит к проблеме сущности (ousia). Эта позиция
характерна для всего классического платонизма, если так можно на-
звать триумвират Платона, Аристотеля и Плотина; она утвержда-
ет, что быть - значит быть смысловой определенностью и, с другой
стороны, обладать законченной смысловой определенностью- значит
быть $[6$, с. 90$]$.

И действительно, если не преувеличивать степень отдаления Аристотеля от его учителя, как это часто было в отечественной литературе, то станет ясно, что аристотелевская óvбí $\alpha$ родственна с платоновским عீбоక в главном - в невозможности принять существование, не соединенное со смысловой определенностью ${ }^{3}$.

\footnotetext{
3Здесь уместно вспомнить известное место из платоновского «Парменида»: «-А относительно таких вещей, Сократ, которые могли бы показаться даже сме-
} 
Между тем, для нашего восприятия аристотелевского слова óvбí более удобно и привычно понимание его не в единстве с породившей этот концепт предшествующей традицией, а, скорее, в том наборе смыслов и значений, которые оно приобрело в средние века. Ключевым моментом в трансформации аристотелевского учения о существовании (как и всей философии Аристотеля) был перевод сочинений Аристотеля на латынь, предпринятый Боэцием в V веке н. э. Боэций использовал для передачи смысла рассматриваемой категории термин «substantia», что можно, в свою очередь, перевести, как «под-основа». Термин «субстанция» вошел в общемировой философский лексикон и большинством философов используется без перевода. Но при обратном переводе на язык Аристотеля «под-основа» скорее была бы переда-

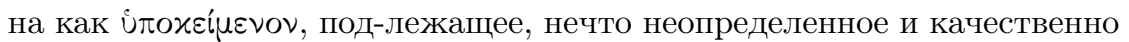
нейтральное ${ }^{4}$. Эта, не очень масштабная, аберрация смысла сделала, однако, возможным представление о некой бескачественной сущности, которая является источником существования для всякой качественной определенной вещи. Как уже мы замечали выше, именно такое преобразование породило томистское толкование сущего, которое в корне отличается от аристотелевского.

Аристотель же в употреблении понятия о่ $\sigma^{\prime} \alpha$ отталкивается от наиболее употребительного, бытового, значения ее, как имущества, со-

шными, как, например, волос, грязь, сор и всякая другая не заслуживающая внимания дрянь, ты тоже недоумеваешь, следует или нет для каждого из них признать отдельно существующую идею, отличную от того, к чему прикасаются наши руки? - Вовсе нет,- ответил Сократ,-я полагаю, что такие вещи только таковы, какими мы их видим. Предположить для них существование какой-то идеи было бы слишком странно. Правда, меня иногда беспокоила мысль, уж нет ли чего-либо в этом роде для всех вещей, но всякий раз, как я к этому подхожу, я поспешно обращаюсь в бегство, опасаясь потонуть в бездонной пучине пустословия» (Парменид 130c 8-130d 8). В ответ на эти слова Сократ получает замечание, в котором уже заключена вся будущая историческая эволюция платонизма в этом вопросе: «-Ты еще молод, Сократ,-сказал Парменид, - и философия еще не завладела тобой всецело, как, по моему мнению, завладеет со временем, когда ни одна из таких вещей не будет казаться тебе ничтожной» (Парменид 130е).

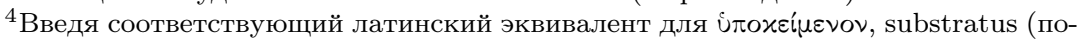
длежащее, букв. - подстилка: см. [5, с. 969]), Боэций не сделал отношение substantia к ỏvбí более ясным. Ситуация усугубилась еще больше в конце XIX века, когда при переводе Аристотеля стали использовать для óvoí $\alpha$ немецкий эквивалент Wesen, откуда и появилась в русских переводах «сущность», термин, который еще менее, чем substantia подходит для выражения аристотелевского слова. Как справедливо замечает современный исследователь, термин «сущность» не выражает адекватно смысл этой категории. Это подтверждается косвенно тем, что соответствующий латинский термин «essentia» никогда не использовался для передачи категории «ousia» (см.: [4]). 
стояния или богатства - именно в таком значении мы встречаем это понятие у Геродота и Еврипида. И хотя в процессе постепенного превращения этого бытового слова в метафору и далее-в философское понятие, оно, усилиями Аристотеля, приобретает все более широкий спектр абстрактных смыслов, но, тем не менее, никогда не отрывается от связи с предметным, качественным бытием. Это подтверждается и самой этимологией слова: óvбí образована от того же глагола «быть» и является particium praesens, причастием настоящего времени уже известного нам глагола віці, предполагая наличие согласованных слов (быть чем-либо). Поэтому для Аристотеля неприемлемым является предположение существования некоего высшего чистого и сверхкачественного бытия, подобного «необходимо сущему» у Аль-Фараби или esse у Фомы, которое как чистый акт бытия, соответствующий глаголу «быть», предшествует бытию той или иной определенной сущности.

Дискуссии вокруг вопроса о том, какой именно смысл вкладывал Аристотель в слово óvбí н не утихают уже несколько веков, а относительно рассуждения о первой и второй сущности в 5 книге «Категорий» (Категории 2а 11-17) не без оснований сказано, что «интерпретация этого пассажа является, возможно, наиболее дискутируемой темой во всей истории философии, от эллинизма до современности» [16, с. 211]. Дело в том, что в своих работах Аристотель использует несколько десятков определений ơv $\mathbf{i} \alpha$, но, подвергая эти определения критическому исследованию, нигде не сообщает, какое именно следует считать верным. Так возникает вопрос: какое из определений óvбí $\alpha$ является для Аристотеля главным в решении вопроса о сущем? Большинство комментаторов Аристотеля склоняются к тому, что под сущностью он понимает единичную вещь, составную чувственную су-

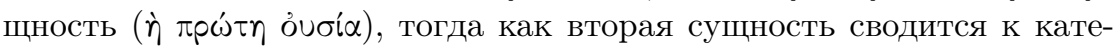
гориям качества. В такой трактовке позиции Аристотеля все отличие его от Платона по вопросу существования общих сущностей сводится к тому, что Аристотель будто бы полагает общие сущности существующими не вне отдельных вещей, но внутри них: не единое вне многого, но единое во многом. В силу своей простоты и понятности, эта гипотеза оказалась весьма распространенной в широких кругах читателей, в популярной и учебной литературе. У нее есть только один недостаток - она сильно искажает действительное положение вещей и, как замечает А. Юрченко, «эта позиция не выдерживает столкновения с высказываниями самого Аристотеля. А. Тренделенбург, излагая сходную позицию в этом вопросе, заметил, что сам Аристотель с подобным мнением, скорее всего, не согласился бы» [13, с. 18]. 
Обратимся к широко известному рассуждению Аристотеля о значениях сущности, в котором он говорит, что из всех родов сущего самым первым сущим (первым во всех отношениях) будет сущность, ибо только она способна существовать самостоятельно и отдельно (Метафизика 1028a). О сущности говорят в четырех основных значениях: чтойность (

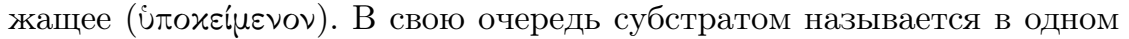

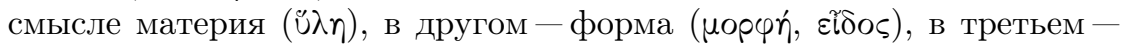
то, что из них состоит (Метафизика 1028b 35-1029a 5). В наибольшей мере сущностью считается субстрат. Это то, о чем сказывается все остальное и что само не сказывается ни о какой сущности, то есть подлежащее, носитель качеств, отвечающий всегда на вопрос «что?» и никогда - на вопрос «какой?». Из сказанного Аристотелем ясно, что он никак не предполагает сведение всех четырех значений сущности к одному, к единичной вещи. Еще более сложной становится ситуация, когда мы вспоминаем о понятиях первой и второй сущности. Некоторые современные исследователи считают необходимым выразить различие между первой и второй сущностью, разделив категорию óvбí $\alpha$ на субстаниию и сущность, увеличив тем самым число Аристотелевых категорий до одиннадцати: «если сопоставить разделение категории „ousia“ на первую и вторую с основным понятием философского учения Аристотеля, то вторая, т. е. сущность в собственном смысле слова, соответствует формам вещей, а первая, или субстаниия-вещам как соединению форм с материей» [4].

Аргументы против эффективности подобного расширения были высказаны еще в 1862 году, в докторской диссертации Франца Брентано, который убедительно обосновал невозможность сведения содержания óvбí $\alpha$, так же, как и всех остальных категорий, к одному или нескольким, раз и навсегда зафиксированным, значениям [17]. Так происходит потому, что категории у Аристотеля всегда представлены одновременно в логическом, грамматическом и онтологическом смысле, и, в соответствии с контекстом, в котором речь идет о сущности, на первый план выходит то или иное их значение, связь между которыми осуществляется через понятие бытия, но не прямо, а посредством аналогии. Брентано говорит: «Таким образом, ясно, что „бытие“ является омонимом для различных категорий, и что они поименованы не случайно (homonyma apo tyches), но по аналогии» [17, с. 66].

Массу вопросов и недоумений вызывает аристотелевское выраже-

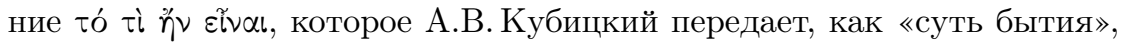
а А.Ф. Лосев как «чтойность», хотя понятно, что использование дан- 
ных эквивалентов является компромиссом между требованиями адекватности греческому оригиналу и понятности его для современного читателя. На трудности в переводе этого выражения указывал и B.В. Розанов:

Термин этот впервые введен в философию Аристотелем и, подобно некоторым другим его терминам, имеет странный, грамматически необычайный склад. Понятие, в нем выраженное, имеет не только важное, но и господствующее значение в его системе [...] под сложным

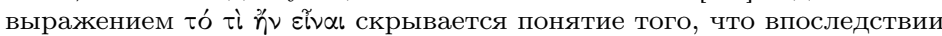
схоластическая философия обозначила термином causa formalis, To есть форма, но не как геометрическое очертание только, а как зиждущее начало всякого предмета или явления, как его понятие. Выраже-

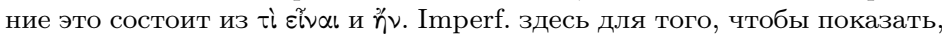
что форма единичного предмета или явления существует не только в текущий момент их пребывания, но что она из века была и предопределяла это пребывание и, с другой стороны, что, когда единичная реальная вещь исчезла, она еще продолжает существовать. Мы передали его выражение: «основание, в силу которого что-либо есть то, что оно есть и чем было», потому что по своей общности оно ближе всего определяет сущность каждой вещи или явления и указывает на положение, которое занимает сущность по отношению к свойствам и к другим сторонам бытия данной вещи или данного явления [3, с. 37-38].

В.В.Бибихин замечает, что в этом вопросе В.В. Розанов остановился на полпути:

Предложенное им длинное «основание, в силу которого что-либо есть то, что оно есть и чем было», он сам вскоре развертывает и упрощает. Новая формулировка («то, что делает то, в чем оно есть, тем, что оно есть») явно не окончательная. В таком виде его версия тоже зовет думать и искать, показывает обещающую перспективу [3, с. 11].

Эта перспектива, как становится ясно спустя более чем столетие, существенно определяется собственной позицией исследователя. В.В. Розанов, работая над переводом Аристотеля, был захвачен своей концепцией, разрабатывавшейся им в труде «О понимании», и, вероятно, именно этим объясняется его тезис о том, что вопросительным местоимением Аристотель «вшифровал» в это выражение неустранимость недоумения. Ж.-Ф. Куртин и А.Рейксбарон, авторы обсто-

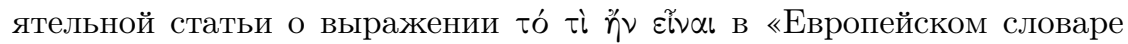
философий» [7, с. 140-147], убедительно показывают, что существует множество (возможно, бесконечное) путей интерпретации данного выражения, причем каждая из этих интерпретаций будет достаточно обоснована, а несколько десятков из них уже реализованы в комментаторской и исследовательской литературе. Весьма привлекательным, 
емким и содержательно определенным выглядит предложенный переводчиком статьи А. Паничем вариант украиноязычного эквивалента «чимбутність».

Резюмируя со своей стороны все вышесказанное, мы утверждаем, что, поскольку Аристотель приступает к вопросу о сущем в условиях терминологической неопределенности, его позиция по вопросу о том, что есть сущее, как это понятие соотносится с понятиями бытия, сущности, субстрата, рода и вида, так и остается окончательно не определенной. Эта неопределенность носит принципиальный характер: Аристотель не излагает завершенное учение о сущем, он исследует названные понятия, почти никогда не останавливаясь на одном из полученных результатов. Эта незавершенность вообще характерна для творческой манеры Аристотеля, он часто завершает исследование констатацией того, что «вопрос, как оказалось, труден». Всякая попытка придать недостающую определенность мышлению Аристотеля может быть (и почти всегда бывает) успешно оспорена. Но именно благодаря исследовательской и языкотворческой деятельности Аристотеля стала возможной работа, начатая Марием Викторином и позже продолженная Боэцием, по переводу греческих слов в строгие философские термины латыни, которые, утеряв богатство и даже избыточность содержания, вместо них приобретают в последующей философской речи содержательную определенность, находят четкие границы объема и выстраиваются в упорядоченное множество философского лексикона. И задача историка философии состоит также в том, чтобы проследить пути формирования этого лексикона. Это позволит нам лучше понять не только греческих философов, стоявших в начале этого пути, но и те процессы трансформации философского языка, которые сегодня формируют панораму нашей философской ситуации.

\section{Литература}

[1] Apистотель. Категории // Аристотель. Сочинения. В 4-х т. - М. : Мысль, 1978. - Т. 2. - С. 51-91.

[2] Aристотель. Метафизика // Аристотель. Сочинения. В 4-х т.М. : Мысль, 1976. - Т. 1. - С. 63-369.

[3] Аристотель. Метафизика. - М. : Институт философии, теологии и истории св. Фомы, 2006. 
[4] Борисов B.H. О смысле категории «оusia» в философии Аристотеля / [Электронный ресурс] // Вестник Самарского государственного университета. Гуманитарная серия. Философия. - 1996. - № 1. - Режим доступа: http://vestniksamgu.samsu.ru/gum/content/phyl.html

[5] Дворецкий И.Х. Латинско-русский словарь. - М. : Русский язык, 1976.

[6] Доброхотов А.Л. Категория бытия в классической западноевропейской философии. - М. : Издательство Московского университета, 1986.

[7] Європейсъкий словник філософій: Лексикон неперекладностей. T. I. - К. : Дух і Літера, 2009.

[8] Кассен Б. Эффект софистики.-М., СПб. : Московский философский фонд; Университетская книга, 2000.

[9] Kopem Э. Основы метафизики. - К. : Тандем, 1998.

[10] Листопад I. Пролегомени до перекладу «Категорій». Український переклад з огляду на латинський спадок / / Філософська думка. 2011. - № 2. - С. 93-105.

[11] Райл Г. Понятие сознания // Райл Г. Категории.-М.: ИдеяПресc, 2000 - С. 323-338.

[12] Россиус A.А. Гуманитарное образование: порча изнутри / [Электронный ресурс] // Русский Журнал / Обзоры / Образование. 2005. - Режим доступа: http://www.russ.ru/pole/Gumanitarnoeobrazovanie-porcha-iznutri

[13] Юрченко А.И. К проблеме категории «сущность» по «Категориям» // Государство, религия, церковь в России и за рубежом. 2009. - Специальный выпуск к № 1. - С. 15-41.

[14] Aristotelis opera: Vol. I-V. / [Ex regensione Immanuelis Bekkeri]. Berolini : Edidit Academia Regia Borussica, 1831-1870.

[15] Aristotle. The Complete Works of Aristotle. Revised Oxford Translation / [Edited by Jonathan Barnes]. - Vol. 1-2. - Princeton : Princeton University Press, 1984. 
[16] Athanasopoulos K. Ousia in Aristotle's Categories // Logique et Analyse. - 2010. - Vol. 53. - No. 210. - P. 211-243.

[17] Brentano F. On the Several Senses of Being in Aristotle. - Berkeley; Los Angeles; London: University of California Press, 1975.

[18] Dancy R. Aristotle and existence // Synthese. - 1983. - No. 54. P. 409-442.

[19] Kahn Ch. The Verb «Be» in Ancient Greek. - Indianapolis; Cambridge: Hackett Publishing Companie, Inc., 2003.

[20] Owens J. The Doctrine of Being in the Aristotelian «Metaphysics». Toronto : Pontifical Institute of Mediaeval Studies, 1951.

Надійшла до редакиії 8 лютого 2012 р. 